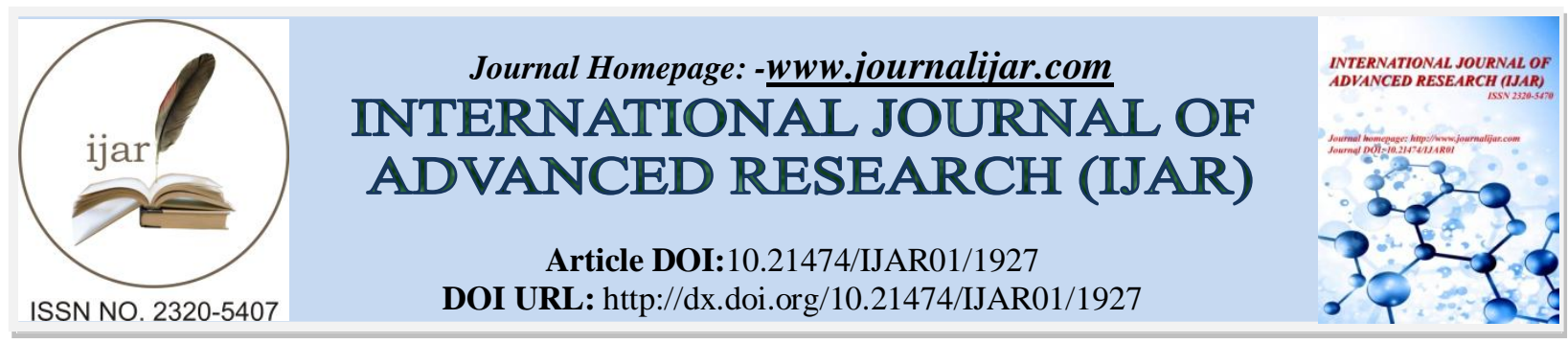

RESEARCH ARTICLE

\title{
DETERMINANTS OF THE MARKETED-PIG PER SOW PER YEAR FOR DECISION-MAKING OF PIGGERY ENTREPRENEUR IN SOUTH KOREA.
}

TaeWan Kim.

Swine Science \& Technology Center, Gyeongnam National University of Science and Technology, Jinju 52725, South Korea.

\section{Manuscript Info}

Manuscript History

Received: 12 August 2016

Final Accepted: 22 September 2016

Published: Ocotber 2016

Key words:-

MSY, piggeryenvironments,

productivity indicator, decision-making.

\section{Abstract}

This study was done to induce efficiently environmental management of piggery via an empirical analysis how much a variety of environmental factors give influence on marketed pig per sow per year (MSY) in production of pig. 30 Pig farms were surveyed for analyses of pig rearing environmental factors, productivity index, and income index. The collected data were examined for influenceon MSY owing to these factors via a multipleregression model.According to results of model estimation, if mortality rate of pigs increased 1\%, MSY reduced 0.18 heads, whereasif a number of sows increased 1 head, MSY reduced rather 0.007 heads. When the marketing day and estrus interval delayed and increased 1 day,MSY reduced 0.095 and 0.534 heads, respectively.Therefore, in order to improve MSY, entrepreneur to manage a piggery is a critically important to reduce mortality rate via decrease of harmful gas in piggery.

Copy Right, IJAR, 2016,. All rights reserved.

\section{Introduction:-}

Gross domestic products (GNP) have been untiringlyincreased atSouth Korea, but agricultural productsgradually decreased. During this period,the proportion of pig products occupied in agricultural products is accounted for $14 \%$ of 47,292 billionKRW in 2014 (MAFRA, 2015). In response to increase of foreign-imported pork in excellent price competitiveness according to import liberalization and tariff barrier elimination of livestock products, South Korea pig industry to develop in a stable industry with international competitiveness must be maximized for productivity via meticulous management and environmental construction to maximize genetic potential of pigs. Although human is able to adjust a life with some control or complement in the given environment, pig livesin a state that has already lost the ability to control their environment.Therefore, human must be made to maximize pig production capacity as control or supplement to a variety of environmental conditions of pigs.

As MSY is an index to indicate how many pigs are shipped by a sow per year, it is critically important because of an indicator that shows the final results of pig farm (Kim and Kim, 2009). The indicator is affected by a variety of factors such as litters per sow per year (LSY), litter size, growing rate, and marketing day. The components of LSY include weaning to estrus interval, farrowing interval, farrowing rate, and gestation length,breed,pregnancy rate, gestation length,parity number,lactation length, non-productive days, andrearing environment.Litter size is influenced by genetic and environmental factors such as breed, gilt management, parity number, disease, stress, and boar fertility (Jose et al.,2015; Lawlor and Lynch, 2007). 
Growth of pigs isdetermined by factors such as rearing pen temperature, air flow, rearing pen floor state, rearing pen structure, and hygiene state, but the most decisive influence is an overcrowded rearing(Kornegay andNotter, 1984). Since overcrowded rearing induces a significant increase in diet competition and aggression, and causes a contracted pig of a low rank, the rearing method reduces pig productivity (Ko and Kim, 1993). In addition, since pigs are nonsweating livestock, the productivity is subject to many influences at higher temperature than lower temperature. Males in high temperature environment affect the lowering of productivityincluding decreases of libido, in sperm production capacity, in sperm injection amount, and in quality of semen, whereas high temperature cause to reducefertilization rates in sows due tochange in estrous cycle, ovum abortion, ovum malformation, anovulation, and early embryo death and resorption (Kim et al., 1995). Furthermore, litter size and piglet weight at birth and weaning are components of production to significantly affect the biological efficiency of sows and the profitability of farms (Jesus et al., 2016).

Pathogens to cause respiratory disease of pigs including bacteria, virus, mycoplasma, and fungi are sensitive to natural environment such as humidity, temperature, and ultraviolet (Done, 1991). Bacteria to be propagated through air grow well below $50 \%$ or above $80 \%$ humidity (Wright et al., 1968). When temperature and humidity were maintainedin lower level, ammonia concentration and dust quantities were increased in the overcrowded rearing piggery (Drummond et al., 1981; Curtis et al., 1983). When relative humidity is low, growth rate of pig is low, and the condition leads to a rearing environment of high failure due to high ammonia gas and falling bacterial number(Jeonget al., 1996).

On the other hand, it has emerged a problem thatpig farmers must be the most urgently settle for production improvement as well as for solution of environment issues to eliminate the harmful gases and odors as problems arising from piggery. The main components of these malodoroussubstances and harmful gases have been originated from amines such as ammonia, sulfur compound such as hydrogen sulfide, and volatile fatty acids (Zahn et al., 2001; Otto et al, 2003; Ra et al, 2004). Since these harmful gases affect growth of pig as well as health of piggery employees, reduction of the harmful gases has emerged as an important variable in persistence of pig industry.

Although various environmental factors that exist in pig farm has not only given a direct and indirect effects on productivity of pig, but has given impact to income of farmers, these environmental factors have been limited for a study how much have influences in productivity. However, in order to increase MSY, the decision-making of piggery entrepreneurfor some of the environmental factors to be centrally managed is directly related with theirs income. Therefore, in this study, the environmental factors that are present in various ways in course of pig production empirically analyze how much affect MSY.

\section{Materials and Methods:-}

\section{Selection of surveying farms and surveying items:-}

The surveyof pigsty environment in this study were selected from 30 farms in 11 cities including Changwon, Tongyeong, Gimhae, Yangsan, Uiryeng, Haman, Goseong, Hadong, Sancheong,Hamyang and Geochang in South Korea. Average herd size of the surveyed farms maintained 2,413 heads, and among them, average full-time sow population accounted for $9.6 \%$ of total herd size (Table 1 ).

Table 1:- Rearing size by breeding stage of surveyed pig farms.

\begin{tabular}{|c|c|c|}
\hline & Total number of pigsin thirty farms & Average number of pigs per farms \\
\hline Sows & 6,951 & 231.7 \\
\hline Piglets & 27,462 & 915.4 \\
\hline Pigs & 37,981 & 1,266 \\
\hline Total & 72,394 & $2,413.1$ \\
\hline
\end{tabular}

The surveying contents were a rearing environment including methodwhich treatspig manure, piggery form, ventilation method of piggery, harmful gas concentration (ammonia and hydrogen sulfide), rearing density, sow piggery illuminance, change of temperature and humidity in piggery, disinfection and cleanliness in pigsty, water contamination (general bacteria, E. coli), and a production environment such as rearing scale, marketing weight and day, MSY, pigs per sow per year (PSY), litters per sow per year (LSY), sow update rate, suckling days, sow estrus interval, farrowing rates, mortality, and artificial insemination rate. The evaluation result of pork determination as an 
indicator of farm income was employed by an internet service (http://www.apgs.co.kr) of Korea institute for animal products quality evaluation (KAPE).

\section{Productivity and income index survey:-}

We surveyed productivity index of pig farm through farm management record diary and interview with managers to directly visit farms. Pork grade evaluation data (meat weight/meat quality) of KAPE directly affected with income determination of farms were obtained from individual farm marketing results via consultation and approval with farmers for information necessary to connect online.

\section{Statistical analysis;-}

The results obtained in survey of rearing environment and productivity index of pig farm were analyzed by multiple linear regression model using REG producer of SAS (1999).

\section{Results and Discussion:-}

Results of surveys for productivity and rearing environment:-

According to summary of data obtained from individual farms, MSY maintained 17.8 heads, and PSY was 20.6 heads as a relatively high level. In addition, farrowing rates maintained over $85 \%$ and LSYexhibited 2.24 rotation. Although suckling days was presentedby relatively long period of 24.1 days, it is assumed that longer suckling period is expanded for disease prevention. Otherwise, Estrus intervals of farrowing sows were investigated by extremely excellent status as average 5.9 days (Table 2).

Table 2:-Productivity index of pig farms.

\begin{tabular}{|c|c|c|c|c|c|}
\hline MSY & PSY & Farrowing Rates & LSY $^{3)}$ & Suckling Days & Estrus Interval \\
\hline 17.8 heads & 20.6 heads & $85.3 \%$ & 2.24 times & 24.1 days & 5.9 days \\
\hline
\end{tabular}

${ }^{1)}$ MSY: marketed pig per sow per year

${ }^{2)}$ PSY: pigs per sow per year

${ }^{3)}$ LSY: litters per sow per year

The A and B grades of meat quantity marked $67 \%$ from the surveyed result of pork grade of the marketed pigs from farms, and $1+$ and 1 grades for meat quality exhibited $60 \%$. The marketing weight and day were averages $111.6 \mathrm{~kg}$ and 181.3 days, respectively (Table 3 ).

Table 3:- Performance of pork carcass grade.

\begin{tabular}{|l|c|c|c|c|c|c|c|}
\hline & \multicolumn{6}{|c|}{ Emergence rate of pork carcass grade (\%) } & \\
\hline \multirow{2}{*}{ Quantity grade } & $\mathrm{A}$ & $\mathrm{B}$ & $\mathrm{C}$ & $\mathrm{D}$ & $\mathrm{E}$ & A\&B grade & Carcass weight \\
\cline { 2 - 8 } & 35.5 & 31.5 & 16.0 & 14.2 & 2.9 & 67.0 & $111.6 \mathrm{~kg}$ \\
\hline Quality grade & $1+$ & 1 & 2 & 3 & & $1+\& 1$ grade & Marketing age \\
\cline { 2 - 9 } & 2.8 & 57.1 & 35.6 & 4.5 & & 59.8 & $181.3 \mathrm{age}$ \\
\hline
\end{tabular}

${ }^{1)}$ Pork carcass grade mean grading results by Korea Institute for Animal Products Quality Evaluation

The survey items related with rearing environment including harmful gas (GasAlertMicro 5, USA), temperature (Micolog Pro RH/Temp, USA), and illuminance (LUX HiTESTER 3423, Japan) were examined by directly visiting farmsat 1-4 PM, September. Ammonia and hydrogen sulfide concentrations of the pig rearing farms were 17 and 2.3 ppm, respectively (Table 4). Ammonia concentrations depending on piggery were examined by 17, 21, and 22.4 ppm in piglet housing, growing housing, and finishing housing, respectively. It is assumed that ammonia concentration was increased in proportion to weight of pig. Pregnancy and delivery housings were observed by relatively low levels as 11.4 and $13.6 \mathrm{ppm}$, respectively. Although hydrogen sulfide appeared to average $2.3 \mathrm{ppm}$, piglet and finishing housings were exhibited by relatively high values as 3.4 and $3.3 \mathrm{ppm}$, respectively.

Table 4:- Harmful gas concentrations according to breeding stage.

\begin{tabular}{|l|c|c|}
\hline & $\mathrm{NH}_{3}$ & $\mathrm{H}_{2} \mathrm{~S}$ \\
\hline Pregnancy Housing & $11.4 \mathrm{ppm}$ & $0.8 \mathrm{ppm}$ \\
\hline Delivery Housing & $13.6 \mathrm{ppm}$ & $1.8 \mathrm{ppm}$ \\
\hline Piglet Housing & $17.0 \mathrm{ppm}$ & $3.4 \mathrm{ppm}$ \\
\hline Growing Housing & $21.0 \mathrm{ppm}$ & $2.3 \mathrm{ppm}$ \\
\hline Finishing Housing & $22.4 \mathrm{ppm}$ & $3.3 \mathrm{ppm}$ \\
\hline Average & $17.0 \mathrm{ppm}$ & $2.3 \mathrm{ppm}$ \\
\hline
\end{tabular}


Average temperature and humidity of pigsty were $25.8{ }^{\circ} \mathrm{C}$ and $60 \%$, respectively. As a result of surveys depending on the breeding housings, piglet housing maintained temperature of an optimum range of $20 \sim 30^{\circ} \mathrm{C}$, but other housings were showed by slightly higher temperature than the range of suitable temperature. It is assumed that this result is owing to summer of higher temperature during survey period and depending on a large seasonal effects by pigpen installed in many farms (Table 5). On the other hand, as illuminances of delivery and pregnancy housings maintained 78 and 117 lux, respectively, the brightness of light in delivery housing was examined to slightly lower. These illuminances was deeply related with breeding, but it is known that growth and feed efficiency have little effect (Acker and Cunningham, 1991).

Table 5:- Temperature and humidity according to breeding stage

\begin{tabular}{|l|c|c|}
\hline Breeding Interval & Temperature $\left({ }^{\circ} \mathrm{C}\right)$ & Humidity (\%) \\
\hline Piglet Housing & 27.83 & 70.00 \\
\hline Growing Housing & 26.79 & 70.00 \\
\hline Finishing Housing & 24.27 & 60.20 \\
\hline Delivery Housing & 26.10 & 48.00 \\
\hline Pregnancy Housing & 24.08 & 52.00 \\
\hline Average & 25.81 & 60.04 \\
\hline
\end{tabular}

\section{Selection of variables;-}

Environmental effect in pig rearing indicates non-genetic factors of sows to formation of offspring(Kaufmann et al., 2000). Although the cause mechanism of these effects are not yet clear, it is estimated that the environment of sows before first fertilization is an impact on the overall productivity and descendants (Sell-Kubiak et al., 2012). Therefore, in this study, as we analyzed productivity of sows to be reared in a specific area in South Korea, rearing environment of pigs were investigated tocorrelation withMSY.

Although factors to affect MSY are determined by mutually direct or indirect effect, the surveyof total contents is not only difficult in terms of time and cost, but becomes difficult of model estimation to occur multicollinearity problems between independent variables. Therefore, it is necessary to be appropriate selection of independent variable to have high explanatory power for MSY. A new variable was obtained while selecting additionally important variables via one by one for selecting a combination of the best described variable. When it will be loss of importance among the selected variables, a variable selection was done by process of releasing the selection variable, stepwise selection method. The result via stepwise selection method was finally selected by 5 for independent variables including pig mortality, hydrogen sulfide, sow heads, marketing age, and estrus interval (Table 6).

Variance explained by regression was $71.6 \%\left(=R^{2}\right)$ of total variance, and this value was significant as 12.12 $(p<0.01)$. Therefore, $71.6 \%$ in the variation of the dependent variable (MSY) was described by 5 independent variables to be selected (Table 7).

Table 6:-Selection of independent variable for MSY using stepwise method.

\begin{tabular}{|l|c|c|c|c|c|}
\hline Variable & Partial $R^{2}$ & Mode $R^{2}$ & $C_{p}$ & F-value & $\operatorname{Pr}>\mathrm{F}$ \\
\hline Mortality rate & 0.4413 & 0.4413 & 15.2530 & 22.11 & $<0.0001$ \\
\hline $\mathrm{H}_{2} \mathrm{~S}$ & 0.1145 & 0.5557 & 8.8009 & 6.96 & 0.0137 \\
\hline Sow heads & 0.0393 & 0.5950 & 7.9027 & 2.52 & 0.1245 \\
\hline Marketing age & 0.0620 & 0.6570 & 5.3219 & 4.52 & 0.0435 \\
\hline Estrus interval & 0.0593 & 0.7164 & 2.9411 & 5.02 & 0.0346 \\
\hline
\end{tabular}

Table 7:- Variance analysis depending on regression model for MSY.

\begin{tabular}{|l|c|c|c|c|c|}
\hline Variable & DF & SS & MS & F-value & Pr>F \\
\hline Model & 5 & 112.2117 & 22.4423 & 12.12 & $<0.0001$ \\
\hline Error & 24 & 44.4270 & 1.8511 & & \\
\hline Total & 29 & 156.6387 & & & \\
\hline
\end{tabular}

$$
R^{2}: 0.7164
$$




\section{Result of model estimation-}

We set model in response to the selection of variables, estimated a parameter value, and examined suitability of these models and performed multi-collinearity test. As a result of examination of validity for the estimated model, Durbin-Watson (DW)value appears on no autocorrelation by 2.335. Eigenvalue of the independent variables had all the positive values. The eigenvalue was not too small compared to 1 as well as were much less than 10 of the maximum condition index. Since multicollinearity does not exist from the result, it is estimated that the result violates various assumptions about the regression model and does not have a problem of multicollinearity (Table 8).

Table 8:- Fitness analysis of the regression model for MSY.

\begin{tabular}{|c|c|c|c|c|c|}
\hline Variable & $\mathrm{DF}$ & $\begin{array}{l}\text { Parameter } \\
\text { Estimate }\end{array}$ & SE & t-value & $\begin{array}{c}\text { Eigenvalue } \\
\text { (Condition Index) }\end{array}$ \\
\hline Intercept & $\mathrm{T}$ & 40.2186 & 6.4993 & $6.19 * *$ & \\
\hline Mortality rate & 1 & -0.1799 & 0.0239 & $-7.52 * *$ & $\begin{array}{c}1.57582 \\
(1.00000)\end{array}$ \\
\hline $\mathrm{H}_{2} \mathrm{~S}$ & $T$ & 0.1104 & 0.0390 & $2.83 * *$ & $\begin{array}{c}1.37328 \\
(1.07121)\end{array}$ \\
\hline Sows & $T$ & -0.0059 & 0.0020 & $-2.94 * *$ & $\begin{array}{c}1.10667 \\
(1.19329)\end{array}$ \\
\hline Marketing age & 1 & -0.0778 & 0.0327 & $-2.38 *$ & $\begin{array}{c}0.81444 \\
(1.39099)\end{array}$ \\
\hline Estrus interval & 1 & -0.5654 & 0.2523 & $-2.24 *$ & $\begin{array}{c}0.69222 \\
(1.50880)\end{array}$ \\
\hline
\end{tabular}

$\mathrm{DW}=2.335$

** $\mathrm{p}<0.01, * \mathrm{p}<0.05$.

As a result, the estimated model of MSY is as follows:

$$
\mathrm{MSY}=40.219-0.18 \mathrm{MR}+0.11 \mathrm{H}_{2} \mathrm{~S}-0.006 \mathrm{SH}-0.078 \mathrm{MA}-0.565 \mathrm{EI}
$$

MSY: Marketed-pig per Sow per Year

MR: Mortality Rate

SH: SowHeads

MA: Marketing Age

EI: Estrus Interval

As the estimated result of the regression model, when mortality rate is increased to $1 \%$ in the rearingpigs, MSY is reduced by 0.18 heads $(p<0.01)$. The mortality rate is known to undergo primarily influence such as average temperature, daily range, relative humidity, and air quality in piggery (Lee et al., 2015; Midwest Plan Service, 1977). When hydrogen sulfide gas concentration was increased to $1 \mathrm{ppm}$, MSY was increased by 0.11 heads, but when sows was increased to 1 heads, MSY was rather reduced by 0.006 heads $(p<0.01)$. Otherwise, when marketing age and estrus interval were increased by 1 day, MSY was reduced by 0.078 and 0.565 heads, respectively $(p<0.05)$. When estrus interval is kept within 4 6 days, sows exhibit the next delivery better than those of more estrus interval for litter size, farrowing rate, and PSY (Almond, 1992). A number of stillborn piglets per sow present the fewest value at 7 13 days (Youn, 2001). Therefore, in order to improve MSY, although it may become a method to reduce non-productive days of sows through shortening estrus interval, it is required attention that this is possible to reduce MSY owing to an increase in the number of stillborn piglets. Otherwise, the increase of sows compared to the former may be careful because of a possibility of rather a negative impact on MSY. MSY was estimated to increase when hydrogen sulfide concentration was increased.However, since the measured gas concentration was in the range of $0.8 \sim 3.4 \mathrm{ppm}$,it is considered that the concentration is very low to no affect the productivity of pig.

\section{Conclusions:-}

In order to increase MSY, we suggest that pig farms must be properly adjusted to temperature and humidity in pigsty depending on breeding stage of pig and must be kept to low mortality through efforts to reduce the concentration of harmful gases. Furthermore, although it is advantageous to induce a shortened marketing day, it is required attention that it is possible to result in reduction of marketing weight and degradation of meat quality.

In the present study, in order to improve MSY by entrepreneur who manages a pig farm, we examined to select an index for the decision how pig management is managed forthe important factors in the course of rearing pigs. However, since the surveyed pig farms were a difference to scale, equipment, and environment, there is a limit to expansion interpretation of the analyzed results. Therefore, this is a problem to be solved for realistically applicationin the future for development of pig farming industry. 


\section{Acknowledgements:-}

This work was supported by Priority Research Centers Program through the National Research Foundation of Korea (NRF) funded by the Ministry of Education (2009-0093813).

\section{References:-}

1. Acker, D. and Cunningham,M. 1991. Animal Science and Industry, 4th ed. Prentice Hall, NJ.

2. Almond, G. W. 1992. Factors affecting the reproductive performance of the weaned sow. Food Animal Practice. 8:503-515.

3. Curtis, S. E. and Kelley, K. W. 1983. Environment and health in the hog house. Proc. Univ. III. Pork. Ind. Conf. 56.

4. Done, S. H. 1991. Environmental factors affecting the severity of pneumonia in pigs. Vet. Rec. 128: 582-586.

5. Drummond, J. G., Curtis, S. E., Meyer, R. C., Simon J.and Norton,H. W.1981. Effects of atmospheric ammonia on young pigs experimentally infected with Bordetella bronchiseptica. Am. J. Vet. Res. 42(6): 963-968.

6. Jeong, H. K., Han, J. H. and Kim, J. H. 1996. Characterization of the drug receptors responsible for intestinal contraction in Israeli carp. Korean J. Vet. Res. 36(1): 131-142.

7. Jesus Ek, M., JoseSegura, C. and Alejandro Alzina, L. 2016. Effect of environmental factor on some litter traits of sows in the tropics Mexican. Rev. MVZ Cordoba 21(1): 5102-5111.

8. Segura-Correa1, J. C., Herrera-Camacho, J., Perez-Sanchez, R. E. andGutierrez-Vazquez, E.2015. Breed and environmental factors of sows and their repeatabilities in central Mexico. RevistaColombiana de CienciasPecuarias. 28(1): 13-21.

9. Kaufmann, D., Hofer, A., Bidanel, J.and Kunzi,N. 2000. Genetic parameters for individual birth and weaning weight and for litter size of Large White pigs. J. Anim. Breed. Genet. 117(3):121-128.

10. Korea Institute for Animal Products Quality Evaluation (KAPE). http://www.apgs.co.kr.

11. Kim,C. W. and Kim, T. W. 2009. Swine Farm Management. Bio-NURI Jinju National University. Jinju. South Korea, P. 90.

12. Ko, Y. D. and Kim,D. H. 1993. Effects of Environmental Factors on Performance and Nutrients Utilizability of Growing Pigs. Kor. J. Anim. Nutr. Feed. 17(4): 183-193.

13. Kornegay, E. T. and Notter, D. R. 1984. Effects of floor space and number of pigs per pen on performance. Pig New Info. 5: 23-33.

14. Lee, T. H., Choi, C.H., Gutierrez,W. M., Kim, I. H., Kim,S. and Chang, H. H. 2015. Study on the Influence of Some Environmental factors on the Mortality Rate of Pigs. Journal of Agriculture \& Life Science. 49(5): 169177.

15. Midwest Plan Service. 1977. Structures and Environment Handbook. MWPS. Iowa State University. Ames. Towa. USA.

16. Ministry of Agriculture, Food and Rural Affairs (MAFRA). 2015. Agriculture, food and rural affairs Statistics yearbook. http://www.mafra.go.kr

17. Otto, E. R., Yokoyama, M., Hengemuehle, S., Von Bermuth, R. D., Van Kempen, T. and Trottier, N. L. 2003. Ammonia, volatile fatty acids, phenolics, and odor offensiveness in manure from growing pigs fed diets reduced in protein concentration. American Society of Animal Science. 81(7): 1754-1763.

18. Ra, J. C., Han, H. J. and Song, J. E. 2004. Effect of Probiotics on Production and Improvement of Environment in Pigs and Broilers. Kor. J. Vet. Publ. Hlth. 28(3): 157-167.

19. SAS. 1999. SAS/STAT Software for PC. Release 8.2, SAS Institute, Cary, NC, USA.

20. Sell-Kubiak, E., Knol, E.and Bijma, P. 2012. Effect of sow history features on growth and feed intake in grower-finishing pigs. J. Anim. Sci. 90:116-126.

21. Wright D. N., Bailey, G. D. and Hatch, M. T. 1968. Role of relative humidity on the survival of air-borne Mycoplasma pneumonia. J. Bacteriol. 96(4): 970-974.

22. Youn, J. W. 2001. The effect of breed, parity, litter size, lactating period, and estrus interval on sow productivity traits in swine. Korean J. Animal Reprod. 23(3): 251-257.

23. Zahn, J. A., Dispirito, A. A., Do, Y. S., Brooks, B. E., Cooper, E. E. and Hatfield, J. L. 2001. Correlation of human olfactory responses to airborne concentrations of malodorous volatile organic compounds emitted from swine effluent. Journal of Environmental Quality. 30: 624-634. 